\title{
Catalytic conversion of ethanol into alkenes and acetaldehyde
}

\author{
Nikoletta Godová, Blažej Horváth \\ Institute of Organic Chemistry, Catalysis and Petrochemistry, Department of Organic Technology, \\ Catalysis and Petroleum Chemistry, Faculty of Chemical and Food Technology STU in Bratislava, \\ Radlinského 9, 81237 Bratislava, Slovak Republic \\ nikolettagoda@gmail.com
}

\begin{abstract}
Bioethanol is an example of a renewable energy source which can be produced not only by fermentation of simple sugars but also by depolymerisation of cellulose, as the second-generation feedstock, in the first step. This will help to further develop the bioethanol economy. Ethanol can be used as a promising platform molecule for the production of a variety of industrially important chemicals such as alkenes or oxygenates. Alkenes are produced industrially by petrochemical way mainly from crude oil, a non-renewable energy source. Conversion of ethanol to light olefins using an appropriate catalyst could replace the production of these key building blocks for the chemical industry.

In this work, the focus is on the preparation and testing of heterogeneous catalysts in the transformation of ethanol to alkenes and acetaldehyde. In most cases, magnesia-based catalysts were used on a silica support during the experiment. Individual types of catalysts were compared in terms of yields of particular products, the effect of the feedstock load and that of calcination temperature of the catalyst on the catalytic activity are discussed. The highest ethylene yields (95\%) were achieved over an Mg- $\beta$-zeolite catalyst; the highest yield of 1,3-butadiene (29.1\%) was achieved in case of an Na/alumina catalyst; and the highest acetaldehyde yield $(22.3 \%)$ was achieved using a K-doped $\mathrm{MgO} / \mathrm{SiO}_{2}$ catalyst.
\end{abstract}

Key words: acetaldehyde, alkenes, ethanol, heterogeneous catalysts, Lebedev process

\section{Introduction}

By the first half of the last century, the chemical industry feedstocks were based mainly on coal, petroleum and inorganics. Due to the development of the petrochemical industry and oil processing, more than half a million products are produced today using a catalyst (Makshina et al., 2014). Fossil fuels are the major energy sources used in the world today. Though the increasing energy and fuel demand and the declining sources of fossil fuels it is a necessity to look for alternative renewable sources of energy. Biomass as a renewable energy source has several important advantages: its use reduces the dependence of the chemical industry on non-renewable resources, and furthermore, biomass-derived chemicals are considered as $\mathrm{CO}_{2}$ neutral. Bioethanol is known as the most widely used biofuel, in $90 \%$ it is produced from biomass and its production continues to grow constantly. (Dias et al., 2009) Rapid development of the bioethanol market has been accompanied by an increasing interest in its use in the production of bio-based chemicals. Significant technological advances have been made in the catalytic conversion of bioethanol, and many important chemicals have been synthesised, for example: ethylene, propylene, hydrogen, 1,3butadiene, acetaldehyde, n-butanol, acetic acid etc. (Zabed et al., 2017)

\section{Production of bioethanol}

Bioethanol is produced by fermentation of substances containing simple sugar or those that can be converted to simple sugars such as starch and cellulose. The most commonly used yeasts in the fermentation of feedstocks are Saccharomyces Sp. and Zymomonas Sp. (Wirawan et al., 2012). Various types of feedstocks can be used to produce bioethanol:

a) First-generation bioethanol involves feedstocks rich in sucrose (sugarcane, sugarbeet and fruits) and starch.

b) Second-generation bioethanol originates from lignocellulosic biomass such as wood, straw and grass.

c) Third-generation bioethanol is made from algal biomass.

Raw feed materials such as sugar cane or sugar beet containing sucrose are fermented by yeasts, which produce ethanol and $\mathrm{CO}_{2}$. After rectification, bioethanol containing up to $96,5 \%$ of ethanol is obtained.

If the feedstock contains starch, the first step of the bioethanol production is mechanical pretreatment, including grinding the grains applying a wet or a dry way. Then, amylases enzymes are added to the mixture. The next steps are the same as in the process with sugar cane.

Lignocellulosic materials consist of three components: lignin, hemicellulose and cellulose. The 
first step in the production of bioethanol from lignocellulosic feedstocks is pre-treatment to break down the lignin structure and release the crystalline structure of cellulose for the hydrolysis. In the hydrolysis steps, lignocelluloses and cellulose are split to oligosaccharides and glucose. The carbohydrate mixture obtained after the hydrolysis is then subjected to fermentation followed by distillation and refining. (Hromádko et al., 2013)

\section{Chemicals from bioethanol}

\section{$C_{2^{-}}, C_{3^{-}}, C_{4^{-}}$hydrocarbons}

Ethylene is a key building block in today's chemical industry. It is primarily produced by steam cracking of light hydrocarbons from fossil feedstocks, and its price is continuously increasing due to the depletion of fossil resources. Another way of ethylene production is by dehydrogenation of ethane and higher alkanes at elevated temperatures. (Chieregato et al., 2016) Ethylene is also produced by ethanol dehydration, the by-product being mainly diethyl ether. The disadvantage of this process is that in case of higher temperature, the dominant product is diethyl ether.

$$
\begin{gathered}
\mathrm{C}_{2} \mathrm{H}_{5} \mathrm{OH} \rightarrow \mathrm{C}_{2} \mathrm{H}_{4}+\mathrm{H}_{2} \mathrm{O} \\
2 \mathrm{C}_{2} \mathrm{H}_{5} \mathrm{OH} \rightarrow \mathrm{C}_{2} \mathrm{H}_{5} \mathrm{OC}_{2} \mathrm{H}_{5}+\mathrm{H}_{2} \mathrm{O}
\end{gathered}
$$

The most commonly used catalysts for the production of ethylene from ethanol are zeolites (H-ZSM-5) and $\gamma-\mathrm{Al}_{2} \mathrm{O}_{3}$ due to their high activity and selectivity. Using $\gamma-\mathrm{Al}_{2} \mathrm{O}_{3}$, ethylene is produced at $400{ }^{\circ} \mathrm{C}$ in an $80 \%$ yield. In case of zeolite $\mathrm{H}-\mathrm{ZSM}-5$, the production takes place at $300{ }^{\circ} \mathrm{C}$ with the ethylene yield of $95 \%$ and the conversion of ethanol of about $98 \%$. (Bi et al., 2010; Phung et al., 2015)

The current demand for ethylene on the market is more than 150 million tonnes per year, of which more than half is consumed in the polyethylene production, especially high density polyethylene (HDPE) produced by Ziegler polymerisation, as well as the low density PE (LDPE and LLDPE) formed by radical polymerization. Large amounts of ethylene are used to produce ethylene dichloride (vinyl chloride-PVC) and ethylbenzene by alkylation of benzene with ethylene and subsequent dehydrogenation. (Zimmermann et al., 2012)

Acetaldehyde is one of the most important aldehydes produced in a large scale in industry. It was produced from ethanol and acetylene in the past but at present, ethylene is the dominant feedstock. (DeWilde et al., 2014) Acetaldehyde is prepared in various ways:

The main method is the oxidation of ethylene by the Wacker process which involves oxidation of ethylene using a homogeneous $\mathrm{Pd} / \mathrm{Cu}$ catalytic system:

$$
2 \mathrm{CH}_{2}=\mathrm{CH}_{2}+\mathrm{O}_{2} \rightarrow 2 \mathrm{CH}_{3} \mathrm{CHO}
$$

A smaller amount can be prepared by partial oxidation of ethanol with oxygen over an $\mathrm{Ag}$ catalyst at the temperatures of $500-650{ }^{\circ} \mathrm{C}$ :

$$
\mathrm{C}_{2} \mathrm{H}_{5} \mathrm{OH}+1 /{ }_{2} \mathrm{O}_{2} \rightarrow \mathrm{CH}_{3} \mathrm{CHO}+\mathrm{H}_{2} \mathrm{O}
$$

Another method of acetaldehyde production, though with little industrial importance, is hydroformylation of methanol using catalysts based on Co, Ni or Fe. The main use of acetaldehyde is the production of acetic acid by catalytic oxidation of acetaldehyde with oxygen over a nickel acetate catalyst. Due to lower costs, acetic acid is currently produced by the carbonylation of methanol (Monsanto process).

Acetic anhydride is prepared in the presence of a manganese acetate and nickel acetate catalysts and a dehydrating agent. The reaction takes place in two steps; first, a ketene is formed

$$
\mathrm{CH}_{3} \mathrm{COOH} \rightarrow \mathrm{H}_{2} \mathrm{C}=\mathrm{C}=\mathrm{O}+\mathrm{H}_{2} \mathrm{O},
$$

which in the second step reacts with another molecule of acetic acid to form acetic anhydride:

$$
\mathrm{H}_{2} \mathrm{C}=\mathrm{C}=\mathrm{O}+\mathrm{CH}_{3} \mathrm{COOH} \rightarrow\left(\mathrm{CH}_{3} \mathrm{CO}\right)_{2} \mathrm{O}
$$

Other important products such as pyridine and pentaerythritol can be obtained from acetaldehyde. (Kirk-Othmer Encyclopedia, 1996)

Propylene also counts among the basic olefins in chemical industry. Ethanol conversion to $\mathrm{C}_{3}$ olefins has been studied over catalysts mainly including zeolites, modified zeolites and metal oxides. Over zeolite catalysts, the formation of $\mathrm{C}_{3}$ olefins has been proposed through an ethylene intermediate and the following acid catalysed oligomerisation-cracking. On supported metal oxides (NiO/MCM-41), ethanol dehydration to ethylene followed by ethylene dimerisation, isomerisation, and metathesis reaction mechanism is reported. (Sun et al., 2014) Consumption of propylene compared to ethylene is much lower but gives higher value-added materials. The main product of propylene processing is polypropylene, produced by polymerisation using Ziegler catalysts. Oxidation of propylene in the presence of a catalyst produces acrylic acid in two steps, where the intermediates are acrolein and acetaldehyde. Propylene oxide is produced by the oxidation of propylene with alkyl hydroperoxides since oxidation with molecular oxygen is not selective enough to result in epoxidation. (Kirk-Othmer Encyclopedia, 1996)

The current production of $C_{4}$ olefins still heavily depends on fossil resources. These olefins are produced as pyrolysis by-products and are separated 
by extractive distillation. The obtained amounts of $\mathrm{C}_{4}$ olefins, especially 1,3-butadiene, does not meet the demand of the butadiene market and therefore new production ways are required. Butadiene is used as a monomer to produce different types of polymers (polybutadiene), copolymers (styrenebutadiene (SBR), butadiene-acrylonitrile (NBR)) and terpolymers (acrylonitrile-butadiene-styrene (ABS)). (Makshina et al., 2014)

Conversion of ethanol to alkenes by Lebedev's process Ethanol conversion into 1,3-butadiene (BD) has a long history in the chemical industry. During the Second World War, BD was produced by the twostep Ostromislensky's process in which ethanol is oxidised to acetaldehyde, which is then reacted with another molecule of ethanol to give butadiene over a mixed oxide catalyst. It was used to produce synthetic rubber in USA and Russia; however, this process was in decline until the end of the $20^{\text {th }}$ century for economic reasons (price of ethanol vs. petrochemical alkenes). In 1929, Lebedev found that butadiene can be synthesised in a one-step process using various heterogeneous catalysts. The overall reaction for the one-step Lebedev's process is:

$$
\begin{gathered}
2 \mathrm{CH}_{3} \mathrm{CH}_{2} \mathrm{OH} \rightarrow \\
\rightarrow 2 \mathrm{H}_{2} \mathrm{O}+\mathrm{H}_{2}+\mathrm{CH}_{2}=\mathrm{CH}-\mathrm{CH}=\mathrm{CH}_{2}
\end{gathered}
$$

The conversion of ethanol to butadiene involves several particular steps: ethanol dehydrogenation to acetaldehyde; aldol addition of acetaldehyde to acetaldol; dehydration of acetaldol to crotonaldehyde or Meerwein-Ponndorf-Verley (MPV) reaction of acetaldol and ethanol to produce 3-hydroxybutanol; MPV reaction of crotonaldehyde and ethanol to obtain crotyl alcohol and acetaldehyde; and dehydration of crotyl alcohol or 3-hydroxybutanol to 1,3-butadiene (Makshina et al., 2015) (Figure 1).
Optimal composition of catalysts for this reaction has been the subject of research for decades. It has been found that the most suitable catalyst for this reaction is the $\mathrm{MgO} / \mathrm{SiO}_{2}$ system, where the yields of $\mathrm{BD}$ were between $9-42 \%$ with the selectivity of 30-84 \%. (Makshina et al., 2014)

\section{Experimental}

\section{Catalysts preparation}

Several catalysts were prepared on conventional supports. If not otherwise specified, all catalyst were calcined in static air at an indicated temperature, pressed at $20 \mathrm{MPa}$, then crushed and sieved to the grain size of $0,3-0,6 \mathrm{~mm}$ :

$\mathrm{MgO} / \mathrm{SiO}_{2}$ catalysts were prepared by mixing $5 \mathrm{~g}$ of $\mathrm{SiO}_{2}\left(\right.$ Aerosil $\left.200^{\circledR}\right)$ and $0.5 \mathrm{~g}$ of $\mathrm{Mg}\left(\mathrm{NO}_{3}\right)_{2} \cdot 6 \mathrm{H}_{2} \mathrm{O}$ in $100 \mathrm{ml}$ of distilled water. The solution was evaporated under vacuum and calcined at $400{ }^{\circ} \mathrm{C}, 500{ }^{\circ} \mathrm{C}$ and $700{ }^{\circ} \mathrm{C}$, respectively.

$\mathrm{Na} / \mathrm{Al}_{2} \mathrm{O}_{3}$ catalysts were prepared by mixing $5 \mathrm{~g}$ of $\mathrm{Al}_{2} \mathrm{O}_{3}$ and $0.5 \mathrm{~g}$ of $\mathrm{NaOH}$ in an incipient amount of distilled water. The solution was dried at $120^{\circ} \mathrm{C}$ over night and calcined at $500{ }^{\circ} \mathrm{C}$.

$\mathrm{K}-\mathrm{MgO} / \mathrm{SiO}_{2}$ catalyst was prepared by mixing $5 \mathrm{~g}$ of $\mathrm{SiO}_{2}\left(\right.$ Aerosil 200) with $0.5 \mathrm{~g}$ of $\mathrm{Mg}\left(\mathrm{NO}_{3}\right)_{2} \cdot 6 \mathrm{H}_{2} \mathrm{O}$ and $0.1 \mathrm{~g}$ of $\mathrm{KNO}_{3}$ in $100 \mathrm{ml}$ of distilled water. The solution was evaporated under vacuum and the dried catalyst was calcined at $400{ }^{\circ} \mathrm{C}$.

\section{Zeolite-based catalysts were prepared as follows}

$\mathrm{Mg}-\mathrm{Clinoptilolite}$ catalyst was prepared by mixing $5 \mathrm{~g}$ of clinoptilolite and $0.5 \mathrm{~g}$ of $\mathrm{Mg}\left(\mathrm{NO}_{3}\right)_{2}$. - $6 \mathrm{H}_{2} \mathrm{O}$ with distilled water for 60 minutes on a magnetic stirrer. After $60 \mathrm{~min}$, the solution was filtered. This ion-exchanging step was repeated three times. The mixture was then filtered and calcined at $600^{\circ} \mathrm{C}$.

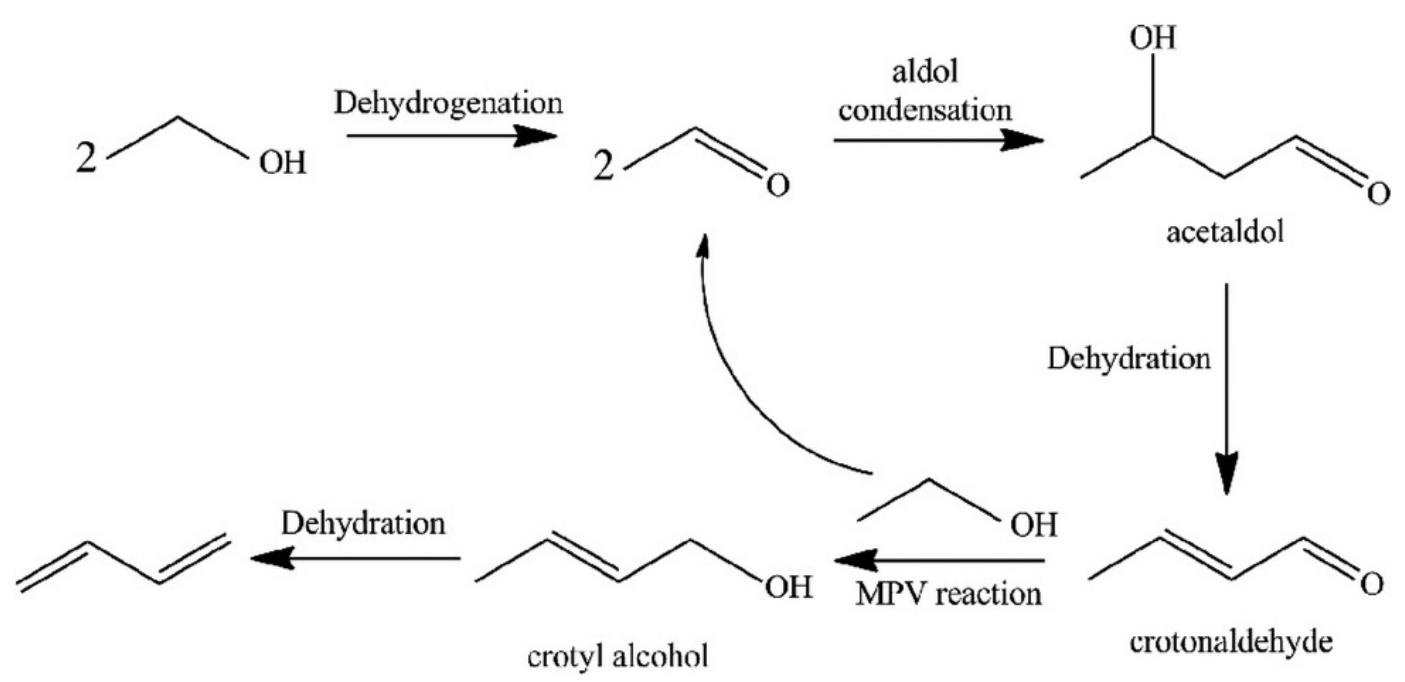

Fig. 1. Generally accepted mechanism of the one-step formation of 1,3-butadiene from ethanol. 
Mg-ZSM-5 catalyst was prepared by mixing $5 \mathrm{~g}$ of synthetic ZSM-5 (module 43) and $0.5 \mathrm{~g}$ of $\mathrm{Mg}\left(\mathrm{NO}_{3}\right)_{2} \cdot 6 \mathrm{H}_{2} \mathrm{O}$ in $100 \mathrm{ml}$ of distilled water. After stirring for 1 hour, the suspension was decanted and then $0,5 \mathrm{~g}$ of $\mathrm{Mg}\left(\mathrm{NO}_{3}\right)_{2} \cdot 6 \mathrm{H}_{2} \mathrm{O}$ was added again and mixed with distilled water. The suspension was ion-exchanged and decanted three times. The decantate was washed and filtrated. The prepared catalyst was calcined at $400^{\circ} \mathrm{C}$.

$\mathrm{Mg}-\beta$ catalyst was prepared by mixing $5 \mathrm{~g}$ of the $\mathrm{H}^{+}$ - form of $\beta$-zeolite and $0.5 \mathrm{~g}$ of $\mathrm{Mg}\left(\mathrm{NO}_{3}\right)_{2} \cdot 6 \mathrm{H}_{2} \mathrm{O}$ and $100 \mathrm{ml}$ of distilled water. It was mixed on a magnetic stirrer - ion exchanged three times. After the filtration, the sample was calcined at $530{ }^{\circ} \mathrm{C}$.

\section{Metal oxide catalyst}

A $\mathrm{CuO} / \mathrm{SiO}_{2}$ catalyst was prepared by mixing $1 \mathrm{~g}$ of $\mathrm{SiO}_{2}$ (Aerosil 200) with $2 \mathrm{~g}$ of $\mathrm{CuO}$ and $10 \mathrm{ml}$ of distilled water; $2 \mathrm{~g}$ of $\mathrm{KCl}$ were added to the mixture and then water was evaporated under vacuum. The sample was dried in an oven at $120^{\circ} \mathrm{C}$, then crushed and sieved without calcination.

\section{Catalysts testing}

Catalytic conversion of ethanol was carried out in a fixed bed inox reactor. The volume of $2.8 \mathrm{ml}$ of catalyst granulate was used. The temperature was controlled using a Fe-Ko thermocouple connected to a PID controller and an electric heating mantle. The reaction was carried out in the temperature range of $300{ }^{\circ} \mathrm{C}$ to $450{ }^{\circ} \mathrm{C}$. The condenser and the collector flask for liquid products were connected to the bottom of the reactor. The off-gas was led to a six-way valve connected to GC. Ethanol was injected by a syringe pump at the flow rate of $5 \mathrm{ml} / \mathrm{h}$. As a carrier gas, $\mathrm{N}_{2}$ was used at the flow rate of $100 \mathrm{ml} / \mathrm{min}$. Prior to the reaction step, the catalyst was heated to a particular reaction temperature in

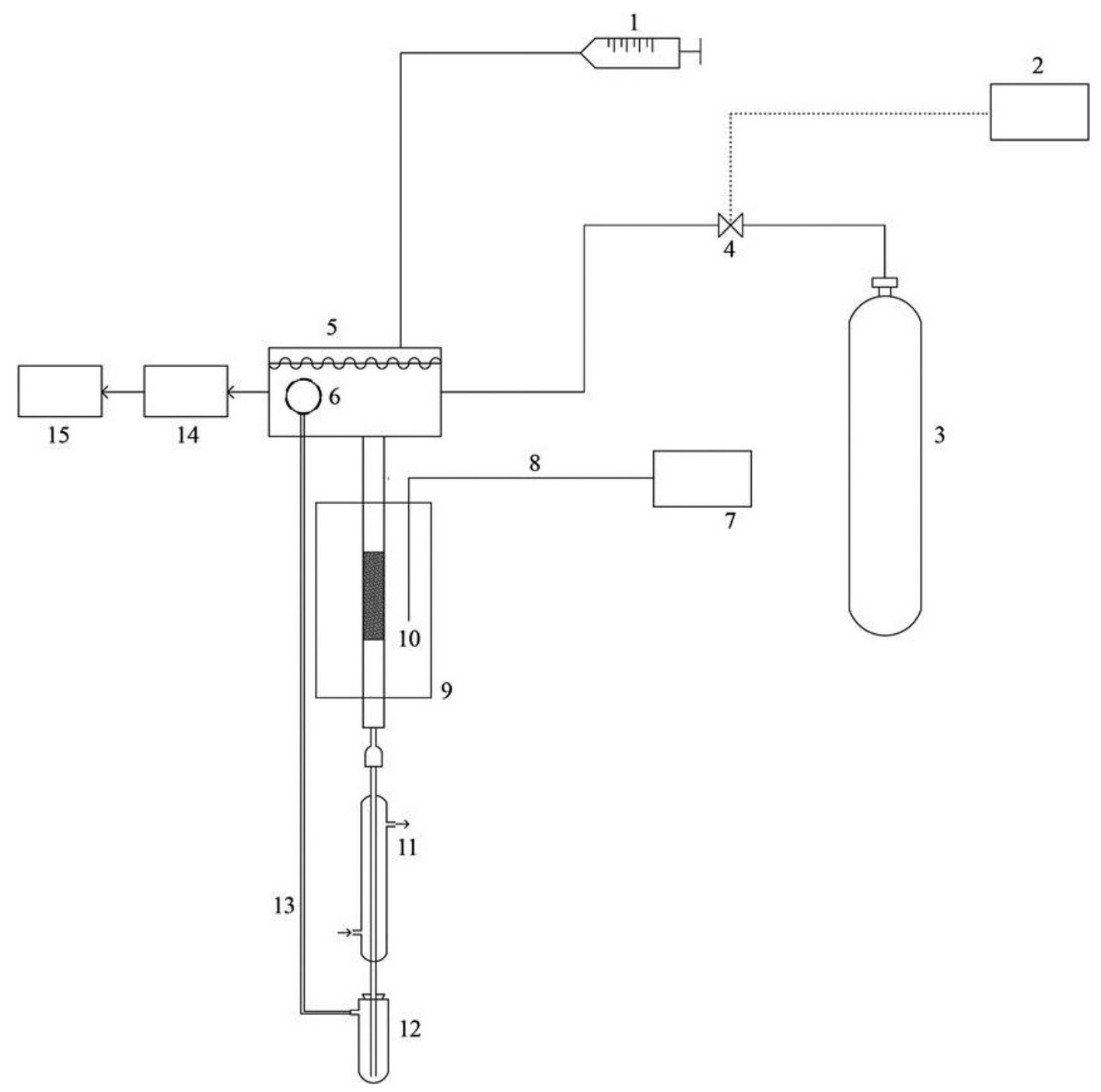

Fig. 2. Equipment used: 1 - syringe pump; 2 - PID controller; 3 - nitrogen cylinder; 4 - solenoid valve; 5 - heated chamber; 6 - six-way valve; 7 - temperature controller; 8 - thermocouple; 9 - reactor; 10 - catalyst in the reactor; 11 - condenser; 12 - products collector; 13 - off-gas; 14 - gas chromatograph; 15 - computer. 
a nitrogen flow. In the next step, the reactants were transferred. The obtained products were analysed by a Chrompack gas chromatograph by dosing of the off-gas by means of the six-way valve in $30 \mathrm{~min}$ periods.

Ethylene, propylene, $\mathrm{C}_{4}$-hydrocarbons, butadiene, diethyl ether and unreacted acetaldehyde were analysed by GC. Liquid products were analysed using a Shimadzu QP-5000 GC/MS. Errors of the determination of individual compounds by GC did not exceed $5 \%$ rel., as confirmed by repeated analyses. The experimental equipment is shown in Figure 2.

\section{Results}

\section{Effect of catalyst calcination temperature}

The last step in the preparation of catalysts was calcination at elevated temperatures, usually at $400-700{ }^{\circ} \mathrm{C}$. For the $\mathrm{MgO} / \mathrm{SiO}_{2}$ catalyst, the influence of the calcination temperature on the product distribution of ethanol transformation is shown in Figure 3.

Samples were collected in all cases in $30 \mathrm{~min}$ periods. As it is shown in Figure 3, the highest yields of each indicated product were obtained using the catalyst calcined at $500{ }^{\circ} \mathrm{C}$. For the catalyst calcined at $400{ }^{\circ} \mathrm{C}$, the yield of $\mathrm{BD}$ was $10.5 \%$ with the selectivity of $28.5 \%$, while the yield of ethylene was only $5.6 \%$ and that of acetaldehyde was negligible. By increasing the calcination temperature to $500{ }^{\circ} \mathrm{C}$, the $\mathrm{BD}$ yields increased to $22.8 \%$ but the selectivity decreased from $28.5 \%$ to $22 \%$. The decrease in the selectivity to $\mathrm{BD}$ was accompanied by higher ethylene yield, $18.5 \%$. For the catalyst calcined at $700{ }^{\circ} \mathrm{C}$, the $\mathrm{BD}$ yields decreased to $5.2 \%$ with the selectivity of $9.3 \%$, and other products such as ethylene (with a $11 \%$ yield) and diethyl ether were present in the reaction products.

\section{Comparison of zeolite-based catalysts with catalysts on conventional supports}

Different types of supports were tested for the catalytic conversion of ethanol to hydrocarbons. Typically, ethanol over zeolites gives a mixture of hydrocarbons including ethylene, $\mathrm{C}_{3}-\mathrm{C}_{4}$ olefins, and $\mathrm{C}_{5^{+}}$ longer chain hydrocarbons via the oligomerisationcracking mechanism. Distribution of the products depends mainly on the reaction temperature and catalyst surface acidity as well as on the promoters in zeolites. Various materials have been proposed in literature (Sun et al., 2014) as catalyst to direct the conversion of ethanol toward BD. Magnesia is supposed to activate the reaction of aldol condensation and assist dehydrogenation, while silica (especially acidic silanol groups) catalyses dehydration (An-
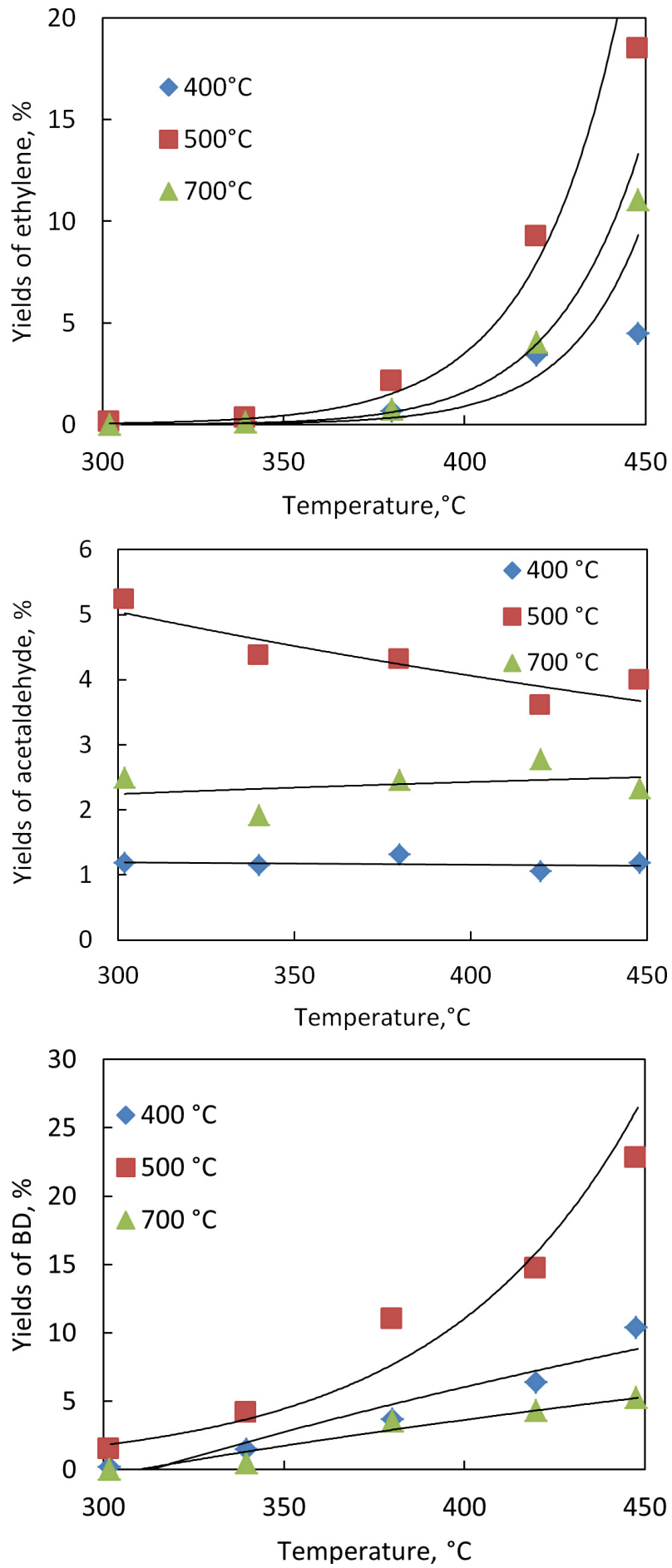

Fig. 3. Effect of calcination temperature on the yields of ethylene, acetaldehyde and 1,3-butadiene

$\left(\diamond\right.$ : calcined at $400{ }^{\circ} \mathrm{C}$, $\square$ : calcined at $500{ }^{\circ} \mathrm{C},{ }^{\star}$ : calcined at $700{ }^{\circ} \mathrm{C}$ ) using $\mathrm{MgO} / \mathrm{SiO}_{2}$ catalyst.

gelici et al., 2015). Different types of catalysts were prepared and tested in our experiments. The two main groups were zeolitic catalysts and $\mathrm{MgO}$-based catalysts on nano- $\mathrm{SiO}_{2}$ support with added promoters. Zeolites (aluminosilicates) are typical acidic catalysts, thus, they promote the formation of ethylene and diethyl ether from ethanol via dehydration, 

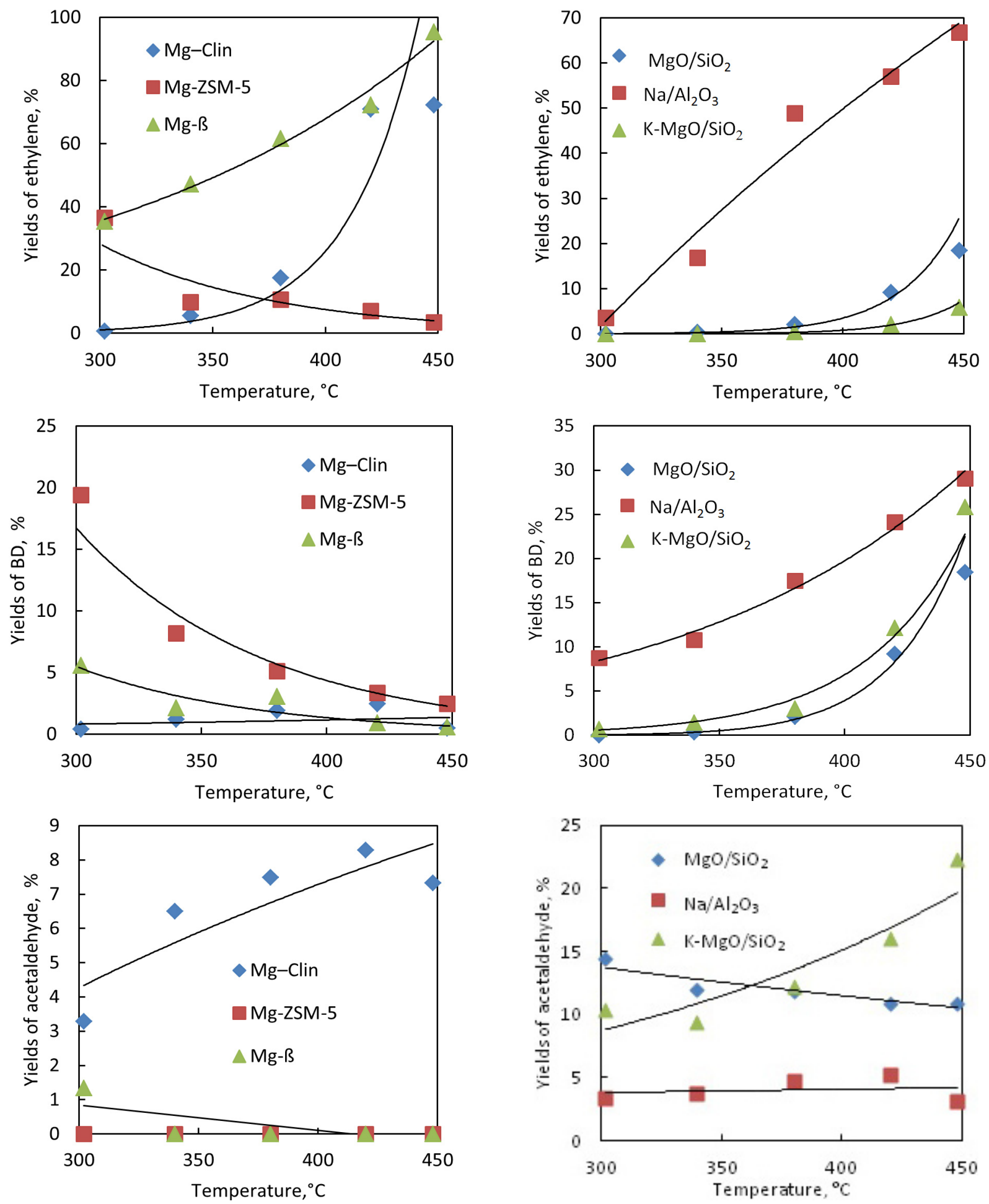

A

B

Fig. 4. Comparison of ethylene, 1,3-butadiene and acetaldehyde yields on zeolitic catalysts

(A) $[\mathrm{Mg}$-Clinoptilolite, Mg-ZSM- $5, \mathrm{Mg}$ - $\beta$-zeolite] with catalysts on conventional supports (B) $\left[\mathrm{MgO} / \mathrm{SiO}_{2}, \mathrm{Na} / \mathrm{Al}_{2} \mathrm{O}_{3}, \mathrm{~K}-\mathrm{MgO} / \mathrm{SiO}_{2}\right]$.

which is in accordance with the observed results. Three types of zeolites (Clinoptilolite, ZSM-5 and $\beta$-zeolite) were compared in terms of the yield of ethylene, acetaldehyde and BD (Figure 4).

Acidic character of zeolites is manifested in the dehydration of ethanol. The ethylene yields on zeo- litic catalyst are higher than those on catalysts on conventional supports. Mg- $\beta$-zeolite led to a $95 \%$ ethylene yield. Catalysts on the $\mathrm{SiO}_{2}$ support showed insignificant ethylene yields which increased with the increasing reaction temperature; however, in case of $\mathrm{Na} / \mathrm{Al}_{2} \mathrm{O}_{3}$, high ethylene yield can also be 
observed. BD yields on zeolitic catalysts decreased with the increasing reaction temperature. At lower temperatures, the BD yields increased and at higher temperatures, more ethylene was produced. The highest BD yield (19.4\%) was reached on the $\mathrm{Mg}$ ZSM-5 catalyst. The results show that the highest BD yield $(29.1 \%)$ was achieved in case of the $\mathrm{Na} / \mathrm{alu}-$ mina catalyst, but the ethylene yield also increased with temperature. In case of the $\mathrm{MgO} / \mathrm{SiO}_{2}$ system promoted with $\mathrm{KNO}_{3}$ during the preparation step of the catalyst, the $\mathrm{BD}$ yields reached $25.9 \%$. It is known that $\mathrm{KNO}_{3}$ upon thermal decomposition to potassium oxide reduces the acidity of the catalyst, thus promoting the formation of $\mathrm{BD}$ and suppressing the formation of ethylene. The yield of acetaldehyde varied from $0 \%$ to $23 \%$, as acetaldehyde is produced either by partial oxidative dehydrogenation of ethanol or by oxidation of ethylene. Ethylene is produced by ethanol dehydration; therefore, the conversion of ethanol to ethylene is more likely in this case than the acetaldehyde formation. The highest acetaldehyde yield, $22.3 \%$, was achieved using the $\mathrm{MgO} / \mathrm{SiO}_{2}$ catalyst with the addition of $\mathrm{KNO}_{3}$ in the preparation step, the production of ethylene is suppressed on this catalyst and the yield of other products, such as acetaldehyde, is favoured. This is demonstrated in Figure 4. Comparing the mentioned catalysts, it has been found that catalysts supported on conventional supports give higher yields of BD and acetaldehyde. It has been confirmed that zeolites promote the formation of ethylene and diethyl ether (not shown).

\section{Effect of catalyst loading}

Over a commercial $\mathrm{MgO}$ catalyst, the effect of catalyst loading was tested by changing the LHSV of the reaction mixture. Gaseous products were analysed by GG at the selected reaction temperature of $380{ }^{\circ} \mathrm{C}$ with the flow rate of ethanol feed of $0.27 ; 1$;
3; 5 and $7.4 \mathrm{ml} / \mathrm{h}$. The achieved results are depicted in Figure 5.

Propylene yields exhibited a surprising maximum at the flow rate of $1 \mathrm{ml} / \mathrm{h}$, as depicted in Figure 5 . Increasing the LHSV resulted in shorter contact time of feedstock with the catalyst. Hence, a decrease in the conversions of all reaction products can be expected. For propylene, this was shown to be true only for higher feed rates $(1-7.4 \mathrm{ml} / \mathrm{h})$. At very low feed rates and thus long contact times, propylene undergoes metathesis reactions with ethylene and other alkenes. Hence, the olefin product distribution can be tuned by the LHSV of the ethanol feed.

\section{Effect of $\mathrm{H}_{2} \mathrm{O}_{2}$ and $\mathrm{H}_{2} \mathrm{O}$ addition to the feedstock}

According to available literature (Zhu et al., 2017), the injection of additional substances to the feedstock can have beneficial effect on the alkene yields. In the following experiments, the effect of hydrogen peroxide and water addition into the reaction mixture was studied. Both substances were added in the ratio of $4: 1$, so ethanol remained to be the major component of the mixture. During these experiments, a metal oxide catalyst was used $\left(\mathrm{CuO} / \mathrm{SiO}_{2}-\mathrm{KCl}\right)$. The yields of ethylene and acetaldehyde using pure ethanol and ethanol- $\mathrm{H}_{2} \mathrm{O}$ and ethanol- $\mathrm{H}_{2} \mathrm{O}_{2}$ feedstocks are depicted in Figure 6 .

The highest yields of ethylene $(0.024 \%)$ and acetaldehyde $(13.97 \%)$ were reached using ethanol as the feedstock with no addition of $\mathrm{H}_{2} \mathrm{O}$ or $\mathrm{H}_{2} \mathrm{O}_{2}$. With the addition of water to ethanol, the yields of ethylene $(0.014 \%)$ and acetaldehyde $(8.09 \%)$ decreased. The same effect was observed upon the addition of $\mathrm{H}_{2} \mathrm{O}_{2}$, when the ethylene yield was $0.008 \%$ and the acetaldehyde yield was $2.31 \%$. Therefore, it can be concluded that such dilution of ethanol with water or $\mathrm{H}_{2} \mathrm{O}_{2}$ has a negative effect

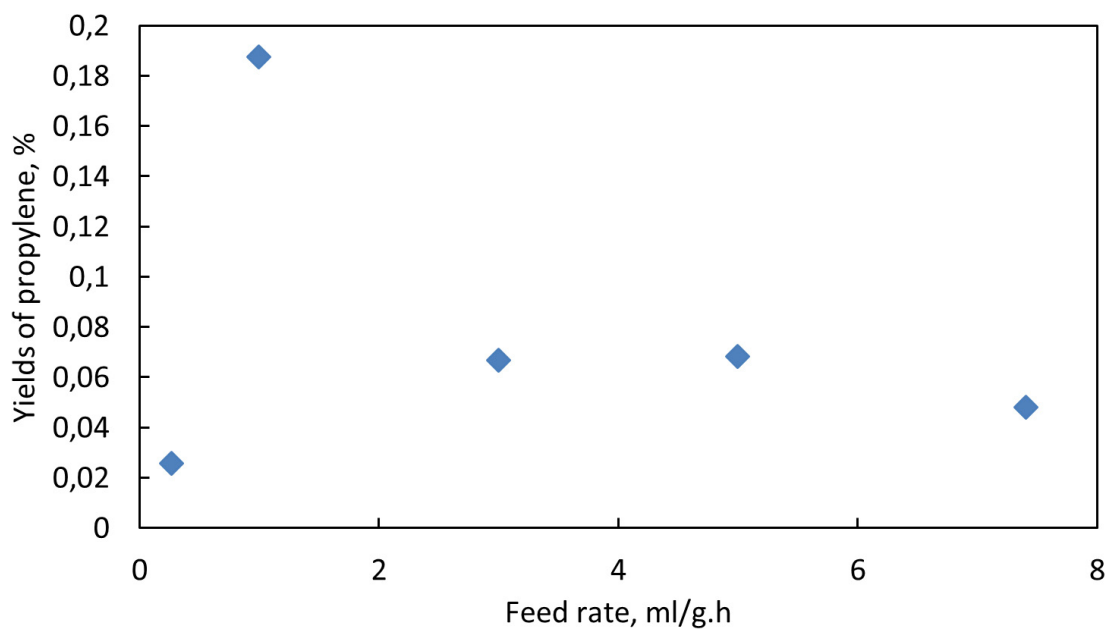

Fig. 5. Propylene yields with changing ethanol feed rate. 

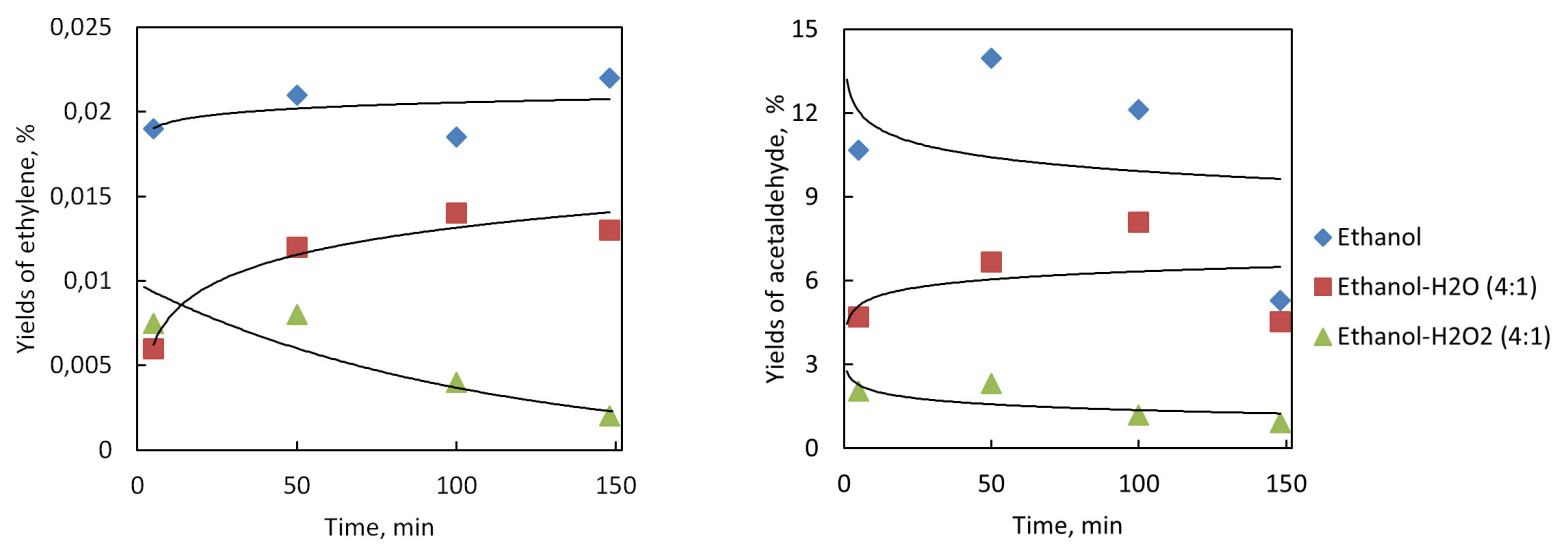

Fig. 6. Ethylene and acetaldehyde yields obtained with different feedstock ( $\bullet$ : ethanol; ". ethanol with water in the ratio of $4: 1 ;^{\wedge}$ : ethanol with $\mathrm{H}_{2} \mathrm{O}_{2}$ in the ratio of $4: 1$ ).

on the alkene yields. On the other hand however, the addition of $\mathrm{H}_{2} \mathrm{O}_{2}$ decelerates the deactivation of the catalyst thus prolonging the catalyst lifetime at the cost of a decrease in the alkene yields.

\section{Analysis of liquid products by GC/MS}

The conversion of ethanol to olefins generates several products. The mixture of gaseous products (mainly ethylene, propylene, C4-fractions, butadiene and diethyl ether) was analysed by GC as reported above. Composition of liquid products can differ from that of the gaseous products and there- fore the composition of liquid products formed over Mg-ZMS- 5 and $\mathrm{Na} / \mathrm{Al}_{2} \mathrm{O}_{3}$ catalysts was analysed by the GC/MS method. (Figures 7 and 8).

As it can be seen in Figure 7, major components of the liquid product are 5-diethyl ether, 10-ethyl acetate, and 15-diethoxy ethane.

In the liquid product mixture over $\mathrm{Na} / \mathrm{Al}_{2} \mathrm{O}_{3}$ catalyst, compounds formed by dehydration of ethanol predominate. Higher alcohols, ketones as well as acetals formed by the reaction of acetaldehyde and ethanol are also present. The main identified compounds were (Figure 8): 11-butanol; 14-pentanone;

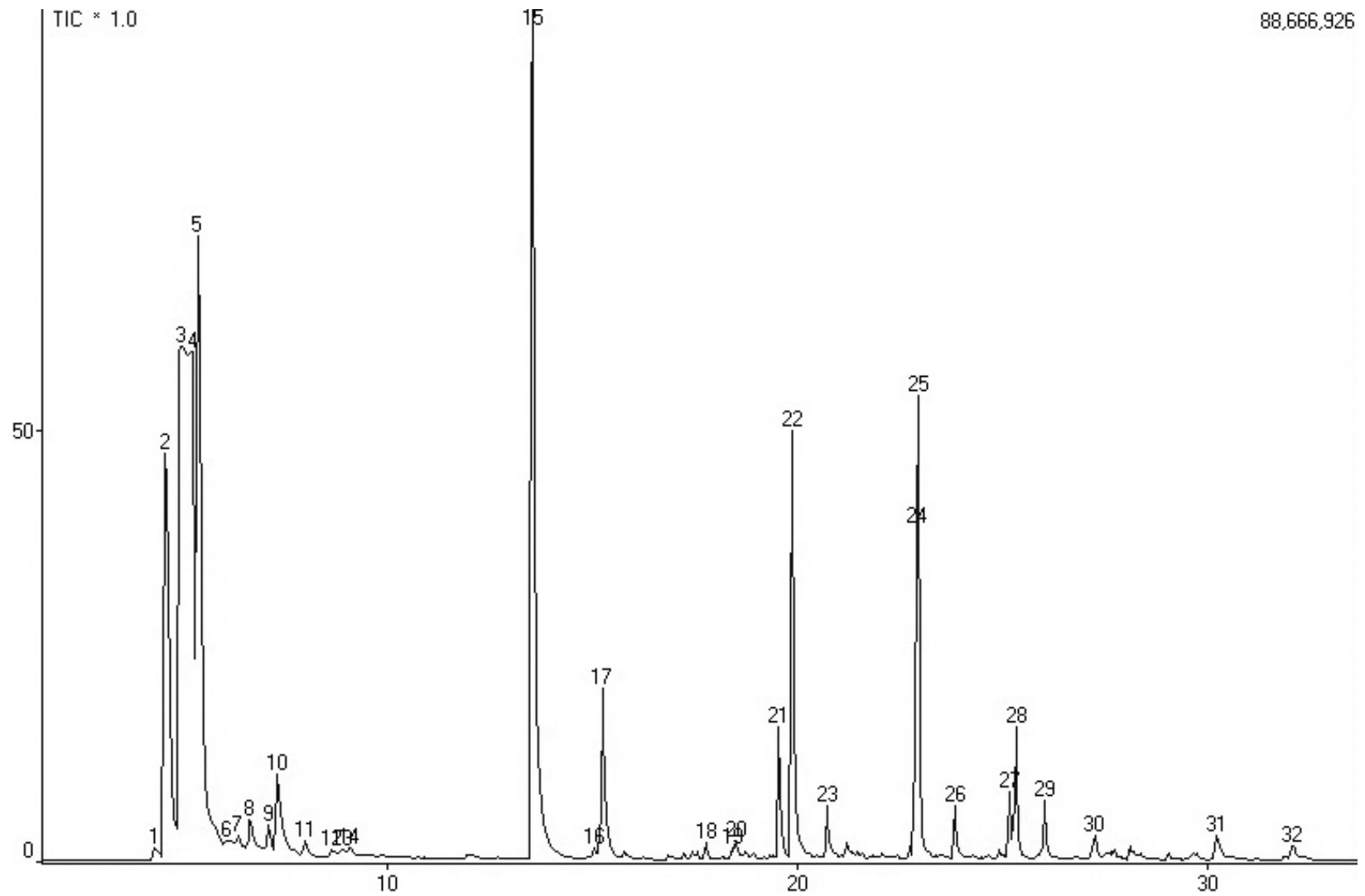

Fig. 7. GC/MS record for products using the Mg-ZSM-5 catalyst. 


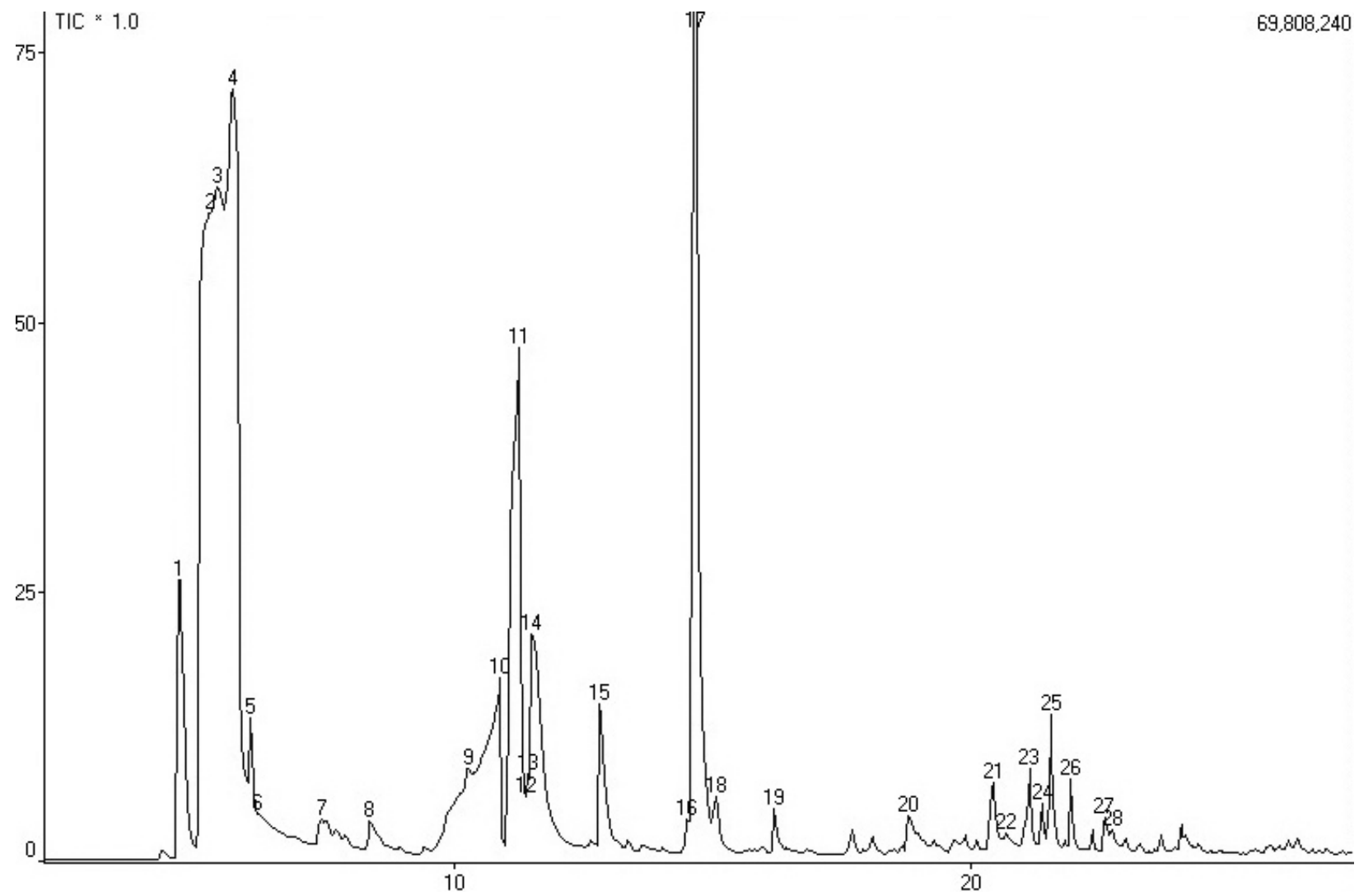

Fig. 8. GC/MS record for products using $\mathrm{Na} / \mathrm{Al}_{2} \mathrm{O}_{3}$ catalyst.

15-ethyl butyl ether; 17-diethyl ether; 25-butyraldehyde diethyl acetal.

$\mathrm{GC} / \mathrm{MS}$ showed that the composition of the mixture of gaseous and liquid products differs noticeably. In the liquid phase, products of the Guerbet's reaction (butanols, perspective fuel additives) as well as acetals dominate.

\section{Conclusion}

The aim of this work was to study catalytic transformations of bioethanol, the main reaction products being $\mathrm{C}_{2}-\mathrm{C}_{4}$ alkenes, acetaldehyde and liquid compounds as butanol and acetals. The reaction was carried out in the gas phase in a fixed bed reactor. Gaseous reaction products were analysed on-line by GC; liquid components were analysed by the GC/MS technique.

$\mathrm{MgO} / \mathrm{SiO}_{2}$ catalysts were calcined at different calcination temperatures, $400{ }^{\circ} \mathrm{C}, 500{ }^{\circ} \mathrm{C}$ and $700{ }^{\circ} \mathrm{C}$, respectively. It was found that the highest yields of ethylene, acetaldehyde and butadiene can be achieved using the calcination temperature of $500{ }^{\circ} \mathrm{C}$. Lower calcination temperatures were found to be insufficient for the decomposition of the magnesium nitrate precursor into the catalytically active $\mathrm{MgO}$ phase. On the other hand, at the calcination temperature of $700{ }^{\circ} \mathrm{C}$, the active $\mathrm{MgO}$ phase reacted with $\mathrm{SiO}_{2}$ to form silicates, which led to a decrease in the butadiene yield and resulted in the formation of ethylene and diethyl ether.

Furthermore, catalysts on nano-SiO $\mathrm{S}_{2}$ supports were compared with zeolite-based catalysts. It was found that zeolites generally promote the dehydration of ethanol to ethylene. The highest ethylene yield over a zeolite-based catalyst was achieved for $\mathrm{Mg}$ $\beta$-zeolite. An addition of potassium to the $\mathrm{MgO} /$ $\mathrm{SiO}_{2}$ catalyst suppressed the production of ethylene by decreasing the acidity of the catalyst and caused an increase in the acetaldehyde yield.

An addition of hydrogen peroxide and water as diluents in the ratio of $4: 1$ over a $\mathrm{CuO} / \mathrm{SiO}_{2}-\mathrm{KCl}$ catalyst decreased the yields of ethylene and acetaldehyde. The dilution of ethanol with water and the addition of $\mathrm{H}_{2} \mathrm{O}_{2}$ suppressed the alkene yields; however, $\mathrm{H}_{2} \mathrm{O}_{2}$ decelerates the deactivation of the catalyst.

In the liquid reaction products, GC/MS revealed the presence of higher alcohols, as butanols along with other oxygenates. In case of the Mg-ZSM-5 catalyst, mainly diethyl ether and diethoxy ethane were present. In the liquid products obtained over the $\mathrm{Na} / \mathrm{Al}_{2} \mathrm{O}_{3}$ catalyst, dietoxy ethane was found as acetal formed from ethanol and acetaldehyde.

Renewable resources can be converted to chemicals which have been produced by petrochemical ways 
so far. Industrial production of bioethanol from cellulose and algae-based sources is extensively developing and allows the production of ethanol in large quantities. The decreasing price of ethanol on world markets makes it a promising raw material for the production of industrially important chemicals. The conversion of ethanol into hydrocarbons, especially to olefins, in the presence of heterogeneous catalysts is one of the industrially promising utilisation of bioethanol, and therefore the development of cheap and robust catalysts for this reaction is inevitable.

\section{References}

Angelici C, Velthoen MEZ, Weckhuysen BM, Bruijnincx PCA (2015) Catalysis Science and Technology 5: 2869-2879.

Bi J, Guo X, Liu M, Wang X (2010) Catalysis Today 149: 143-147.

Chieregato A, Ochoa JV, Cavani F (2016) Olefins from Biomass, in Chemicals and Fuels from Bio-Based Building Blocks (eds F. Cavani, S. Albonetti, F. Basile and A. Gandini), Wiley-VCH Verlag GmbH \& Co. KGaA, Weinheim, Germany, ISBN: 9783527698202.

DeWilde JF, Czopinski ChJ, Bhan A (2014) ACS Catalysis 4, 12: 4425-4433.
Marina OS Dias, Ensinas A, Nebra S, Rubens Maciel Filho, Carlos EV Rossell, Maria Regina Wolf Maciel (2009) Chemical Engineering Research and Design 87: 1206-1216.

Hromádko J, Hromádko J, Miler P, Honig V (2010) Listy cukrovarnické a řepařské 126, 7-8: 267-271.

Kirk-Othmer Encyclopedia of chemical technology, (1996) vol. 20, $4^{\text {th }}$ edition: 48-55: 122-132.

Makshina EV, Dusselier M, Janssens W, Degréve J, Jacobs PA, Sels BF (2014), Chemical Society Reviews 22: 7917-7953.

Makshina EV, Janssens W, Sels BF, Jacobs PA (2012), Catalysis Today 198: 338-344.

Makshina EV, Janssens W, Sels BF, Vanelderen P (2015), ChemSusChem 8(6): 994-1008.

Phung T, Busca G (2015) Catalysis Communications 68: $110-115$.

Sun J, Wang Y (2014) ACS Catalysis 4: 1078-1090.

Wirawan F, Cheng ChL, Kao W-Ch, Lee DJ, Chang JS (2012) Applied Energy 100: 19-26.

Zabed H, Sahu JN, Suely A, Boyce AN, Faruq G (2017) Renewable and Sustainable Energy Reviews 71: 475-501.

Zhu Q, Wang B, Tan T (2017) ACS Sustainable Chemistry \& Engineering, 5 (1): 722-733.

Zimmermann H, Walzl R (2012) Ullmann's Encyclopedia of Industrial Chemistry-Ethylene, vol. 13: 465-526. 